\title{
A emergência do sujeito desejante no discurso do MST
}

Freda Indursky (UFRGS)

\section{Resumo}

No presente trabalho, retorno às designações ocupação/invasão para examinar um registro muito peculiar da designação invasão, ocorrido em uma entrevista com Diolinda Alves de Souza, líder do MST, em 06/12/1995, para a Revista da Folha. Interessou-me, nesta entrevista, examinar o processo de subjetivação/identificação de Diolinda: em um determinado momento da referida entrevista, ao responder sobre sua primeira ocupação, refere-a como invasão. Assim procedendo, a entrevistada não mobiliza o que o sujeito pode/deve dizer a partir de seu lugar discursivo. Esta designação não corresponde ao modo de subjetivar-se Formação Discursiva Sem Terra, tão bem desenhado ao longo da entrevista, até aquele momento. Esse deslizamento de ocupação para invasão permite identificar um processo metafórico específico. Processo metafórico é "um processo não-subjetivo no qual o sujeito se constitui" (Pêcheux, 1988, p. 130). E ainda: processo de metáfora consiste em um "processo sócio-histórico que serve como fundamento da 'apresentação' de objetos para os sujeitos" (idem, p. 132). Entendo que este processo metafórico específico aqui analisado permite vislumbrar o momento em que o sujeito do discurso político é lançado em suas memórias de onde emerge como um sujeito desejante.

Palavras-chave: lugar discursivo; posição-sujeito; formação discursiva; processo metafórico; produção do desejo; agenciamento sócio-político pulsional; sujeito desejante. 
A produção [do desejo] é adjacente a uma multiplicidade de agenciamentos sociais.

(Guattari \& Rolnik)

Era panela, roupas e lona para todo o lado. Papagaio cantando, galinha piando. Uma festa.

(Diolinda Alves de Souza)

\section{Apresentando a questão}

Este trabalho inscreve-se em uma pesquisa que tem como objeto de investigação o discurso do/sobre o Movimento dos Trabalhadores Rurais Sem Terra (MST) na mídia. Em várias ocasiões, trabalhei com as designações ocupação e invasão (INDURSKY, 1999; 2005; 2006, por exemplo). Retomo a elas, nesse artigo, para trabalhar com as possibilidades e limites do sujeito frente aos sentidos que lhe são permitidos e aqueles que efetivamente produz.

A Teoria da Análise do Discurso (AD) ensina que tudo não pode ser dito e que os sentidos podem ser muitos, mas não são nem infinitos, nem qualquer um. Tais restrições sinalizam os limites do dizível e as interdições com que o sujeito do discurso se depara em suas práticas discursivas, as quais são indicativas, entre outras questões, da incompletude da linguagem bem como da divisão e dispersão do sujeito. Eé com estes limites que o sujeito joga em suas práticas discursivas. Essas são as questões que serão mobilizadas no presente trabalho.

Para tanto, vou me ocupar do discurso de uma das lideranças do MST no Pontal do Paranapanema, São Paulo. Trata-se de Diolinda Alves de Souza, mulher de José Rainha, ambos líderes do MST, no Pontal de Paranapanema, na década de 90 do século passado. Vou analisar sequências discursivas (SD) extraídas de duas diferentes entrevistas feitas pela Folha de São Paulo (FSP) com Diolinda. A primeira, em 01.11.95, por ocasião de sua prisão, durante uma manifestação de rua, e a segunda, após sua liberação, em 06.12.1995. Essas SD estão organizadas em dois recortes. O primeiro (SD 1,2,3,4) indica as coerções a que o discurso de Diolinda está submetido e o segundo (SD5) deixa à mostra a ruptura de tais coerções. Ambos constituirão objeto de análise nesse trabalho.

\section{A prática discursiva de Diolinda}

Como vimos em trabalhos anteriores (INDURSKY, 1999; 2006), as lideranças do MST, ao se referirem às práticas desse movimento social, o fazem designando-as por ocupação. E, no discurso de Diolinda, não é diferente. Percebe-se também que o entrevistador, quando se refere às ações do Movimento, designa- 
as por invasão, mas, ao responder, Diolinda "traduz" invasão por ocupação.

Para visualizar o jogo discursivo que se estabelece entre essas diferentes designações no discurso do/sobre o MST, insiro, a seguir, duas sequências discursivas ${ }^{1}$ recortadas da entrevista que Diolinda concedeu à Folha de São Paulo quando se encontrava no presídio de Carandiru.

O MST não radicaliza ao falar de invasões quando o governo fala em negociar?

(Pergunta da $\mathrm{FSP}^{2}$ dirigida à Diolinda Alves de Souza, em Entrevista Coletiva, 1.11.1995, Presídio do Carandiru, SP).

SD1 - A orientação é para que os companheiros continuem ocupando terras.

A prisão de um ou outro líder não vai inibir o movimento.

(Resposta de Diolinda, 1.11.1995, Presídio do Carandiru, SP).

Como é possível perceber, a interlocução se faz entre repórter e líder do MST, em que pese o fato de que cada um desses sujeitos, para poder dizer, precisa se inscrever em seu lugar social (PÊCHEUX, [1969]³ 1990, p. 82). Ao fazê-lo, o repórter identifica-se com a Formação Discursiva (FD) dos proprietários rurais, designando as ações do MST por invasão. Por outro lado, a líder do MST se subjetiva na FD Sem Terra, antagônica à de seu interlocutor, designando tais ações por ocupação. Desta forma, essas sequências discursivas desenham os diferentes lugares discursivos (GRIGOLETTO, 2007) que atravessam essa entrevista - lugar discursivo da imprensa e lugar discursivo de lideranças do MST - bem como as posições-sujeito a partir das quais os envolvidos nessa interlocução enunciam. Tais lugares circunscrevem a cena discursiva (INDURSKY, 1997) em que essa interlocução se trava. A designação ocupação se faz presente no discurso dessa liderança, como pode ser observado nas SD que seguem.

SD2 - As ocupações vão continuar. Isso faz parte dos princípios do movimento. (Entrevista de Diolinda Alves de Souza a Paulo Ferraz, FSP - 16.10.95, p. 1-3).

A primeira SD refere-se à pergunta formulada pelo entrevistador, razão pela qual não será numerada. A segunda SD consiste na resposta dada por Diolinda e faz parte de nosso primeiro recorte discursivo.

2 O jornal A Folha de São Paulo será referido pela sigla FSP.

3 Ao longo do trabalho, as datas entre colchetes remeterão à data da primeira edição francesa. $E$ a data que se lhe justapõe refere-se à data da publicação brasileira consultada.

SD3 - Vão continuar as ocupações e os plantios no Pontal.

(Entrevista Coletiva de Diolinda no Presídio Feminino do Carandiru - FSP - 1.11.95, p. 8).

SD4 - É desculpa do Governo dizer que as ocupações atrapalham a negociação. Nunca houve reforma agrária sem mobilização. (Entrevista de Diolinda no Presídio Feminino do Carandiru - 1.11.95, p. 8).

Como se vê, Diolinda usa a designação ocupação para referir-se às ações do MST, o que é indicativo de que a líder desse Movimento identifica-se com e subjetiva-se pelo viés da designação ocupação. Isto é constitutivo de seu discurso. Diolinda subjetiva-se a partir de seu lugar discursivo de liderança, pelo viés de uma designação já estabilizada e normatizada no discurso do MST, tal como 
4 Meu projeto de pesquisa gira em torno do discurso do/sobre o MST, tal como ele é apreendido através da imprensa. Nesse âmbito, o discurso dos assentados e dos acampados pouco aparece e não se constitui em objeto de minha pesquisa. Outros pesquisadores têm se ocupado do discursos dos sem-terra assentados e acampados e, em suas pesquisas, observaram que, entre os sem-terra, pode aparecer a designação invasão. Já meu trabalho busca apreender e examinar o discurso das lideranças do MST tal como este aparece na imprensa. E, neste âmbito, o sentido normatizado e regulamentado é ocupação, como é possível verificar trabalhos anteriores, referidos no início deste trabalho. ele ocorre na mídia, pois essa designação remete a redes de memória onde ocupação aparece como uma "coisa-a-saber" (PÊEHEUX, [1982] 1990, p. 34) para quem se inscreve no lugar discursivo de uma liderança do MST. Essa coisa-a-saber caracteriza as SD constitutivas de nosso primeiro recorte. E assim é até o momento da entrevista que Diolinda concedeu à Revista da Folha [de SP] em 06.12.95, após ter tido sua prisão relaxada.

Nessa entrevista, Diolinda fala de ocupações, de sua luta pela terra, da acusação de assassinato que pesa sobre seu marido, José Rainha, e também se refere a seu filho. Enfim, responde tranquilamente sobre todas as questões que lhe são feitas, até que, num determinado momento da entrevista, ao ser questionada sobre sua primeira ocupação, refere-se a ela como invasão. Vejamos a sequência discursiva que traz esse registro, o qual vai constituir nosso segundo recorte discursivo e nosso objeto específico de análise e reflexão no presente trabalho.

SD5 - Quando tinha 15 anos, os pais entraram em uma disputa de terra que acabou originando o assentamento Vale da Vitória, perto do Município de São Mateus (ES). O conflito rendeu um lote para os Alves de Souza. E encantou Diolinda: "Me lembro bem daquela invasão. Eufóricas, centenas de famílias levantavam barracos na madrugada. Era panela, roupas e lona para todo o lado. Papagaio cantando, galinha piando. Uma festa".

(Entrevista de Diolinda Alves de Souza à Revista da Folha [de SP], 06/12/95, p. 17) (O destaque é meu).

É este fato discursivo que será objeto de interpretação. Interessa-me refletir sobre o que levou a entrevistada a substituir a designação ocupação, própria à posição-sujeito de liderança que ocupa, pela designação invasão, proveniente do discurso-outro, do discurso próprio à posição-sujeito antagonista, a partir da qual os proprietários rurais ${ }^{4}$ enunciam. É essa troca inusitada que reteve minha atenção. E este processo que consiste em tomar uma palavra pela outra, ou seja, ocupação por invasão, vou chamar, apoiando-me em Pêcheux ([1975] 1988), de processo metafórico.

Em Semântica e Discurso, lê-se que um processo metafórico é "um processo não-subjetivo no qual o sujeito se constitui" (PÊCHEUX, [1975] 1988, p.130). E, um pouco adiante, o autor explicita que ele consiste em um "processo sócio-histórico que serve como fundamento da 'apresentação' de objetos para os sujeitos" (idem, p. 132).

A partir dessas duas formulações sobre a noção de metáfora, vou examinar o registro muito específico de invasão, identificado em SD5. A elas, acrescento uma terceira passagem, citada a partir de outro texto de Pêcheux ([1982] 1990a): um processo metafórico, segundo Pêcheux, possibilita examinar não só sentidos que deslizam, mas também uma possível falha no ritual, como podemos ler na citação que segue:

a interpelação ideológica como ritual supõe o reconhecimento de que não há ritual sem falha, desmaio ou rachadura: "uma palavra 

um ritual chega a se quebrar no lapso ou no ato falho (PÊCHEUX, [1982] 1990a, p. 17) (O destaque é meu).

Interessa-me examinar, nesse trabalho, o processo metafórico ocupação/invasão identificado na prática discursiva de Diolinda, com o objetivo de indagar sobre seu sentido: seria o processo metafórico ocupação/invasão indicativo do que Pêcheux designa na citação precedente de falha no ritual? Seria a palavra invasão tomada em substituição a ocupação, indicativa de que Diolinda teria se desidentificado dos saberes da FD a partir da qual tem se subjetivado ao longo de sua vida de militante e se identificado com a FD em que se inscreve o discurso dos latifundiários? Como interpretar o deslizamento de ocupação para invasão? Essa é a minha questão, aqui.

Inicio minha reflexão, apontando a hipótese com que vou trabalhar: o processo discursivo ocupação/invasão não representa o sintoma de uma quebra no ritual de interpelação ideológica de Diolinda. Enunciar invasão por ocupação, no caso em análise, não significa que ela tenha se desidentificado da FD Sem Terra e tenha passado a se identificar com a FD dos Latifundiários. Este deslizamento pode, quando muito, ser a pista de um vacilo sofrido pelo sujeito desse discurso (PÊCHEUX, [1982] 1990b, p. 314-17). Cabe, a seguir, indagar sobre a natureza desse vacilo.

Frente a essa hipótese inicial, avanço um pouco mais: parece-me que, assim como não ocorreu um processo de desidentificação, tampouco sucedeu um processo de contra-identificação (PÊCHEUX, [1975] 1988, p. 214-7). Este processo metafórico aponta para um outro processo semântico que passo a examinar, a seguir.

Acredito que essa alternância ou batimento, como diz Pêcheux ([1982] 1990c, p. 54), seja uma oscilação momentânea entre o sentido que pode/deve ser dito do lugar discursivo de uma liderança do MST e o sentido que, nesse lugar, está interditado, mas que é produzido mesmo assim.

O deslizamento que estamos examinando vem fortemente marcado pelos "efeitos do interdiscurso [que] se desenvolvem em contradições" diz Pêcheux. ([1984] 2011, p. 157). Para Althusser,

a contradição é inseparável da estrutura do corpo social, considerado em seu todo, onde, aliás, ela se exerce, mostrando-se inseparável de suas condições formais de existência (...) estando, conseqüentemente, por elas afetadas em seu cerne. Ou seja, em um único e mesmo movimento, é determinante, mas também determinada: determinada pelos diferentes níveis e diversas instâncias da formação social ... (ALTHUSSER, 1967, p. 99-100) (Os destaques são meus).

Entendo que esse deslizamento indica uma contradição, sim, mas não implica a ruptura com o próprio discurso e a deriva para o discurso-outro, afetado pela FD antagônica. Essa passagem de ocupação para invasão indica mais bem uma apropriação do discur- 
so-outro. Como veremos, a seguir, ele aponta para algo diferente da ruptura: no momento em que o sujeito do discurso se apropria desta designação, a contradição se instaura em seu discurso. É ainda Pêcheux que ilumina essa contradição, pois tanto ocupação quanto invasão são

conjunturalmente determinados enquanto objetos ideológicos; nem universais históricos, nem puros efeitos ideológicos de classe, esses objetos teriam a propriedade de ser ao mesmo tempo idênticos a eles mesmos e diferentes deles mesmos, isto é, de existir como uma unidade dividida, suscetível de se inscrever em um ou outro efeito conjuntural, politicamente sobre-determinado. (PÊCHEUX, [1984] 2011, p. 157) (Os destaques são meus)

Diolinda, ao inscrever a designação invasão em seu discurso, vacila, não entre uma FD e outra, mas entre uma designação e outra, entre uma posição de sujeito e outra, entre a posição de um sem-terra e a posição de um líder, mas tal vacilo ocorre no interior da FD Sem Terra e, assim procedendo, é o sentido de invasão que desliza. Ou seja: uma palavra pela outra, sim. Invasão por ocupação, sim. Mas não se trata da ruptura do ritual ideológico de interpelação de Diolinda, e sim de um deslizamento, de um vacilo do sujeito entre sentidos. Dito de outro modo, não é Diolinda que desliza de uma FD a outra, mas é o sentido de invasão que desliza, ao passar da FD dos latifundiários para a FD Sem Terra. Ouçamos, mais uma vez, a palavra de Pêcheux:

\begin{abstract}
é porque os elementos da sequência textual, funcionando em uma formação discursiva dada, podem ser importados (meta-forizados) de uma sequência pertencente a uma outra formação discursiva que as referências discursivas podem se construir e se deslocar historicamente. (Ibidem, p.158).
\end{abstract}

Relembrando aquele momento que viveu, Diolinda se depara com o real da língua que aponta para o impossível de dizer, dá de encontro com aquilo que, de seu lugar discursivo, lheé interditado, mas que, sob o efeito da emoção, torna-se impossível de dizer de outro modo (PÊCHEUX, [1981] 2004, p. 52). É a própria contradição que pode ser flagrada através da bipolarização representada nesse processo metafórico determinado "pelos diferentes níveis e diversas instâncias da formação social" para retomar as palavras de Althusser.

Mas, o que move esse discurso e o sujeito que o enuncia? Entendo que essa dualidade é um sintoma da emergência do sujeito desejante que se mostra pelo viés da contradição, no momento em que Diolinda rememora aquele acontecimento fundante de sua subjetividade sem-terra, momento que a impregna, uma vez mais, pelo viés da memória afetiva, de alegria incontida e a faz equivocar-se, a faz deslizar pelos sentidos, a faz produzir poesia - Era panela, roupas e lona para todo o lado. Papagaio cantando, galinha piando. Uma festa. - instaurando, no interior do discurso do MST, um processo metafórico que re-significa o discurso-outro para poder 
incorporá-lo ao seu discurso. Diria que esse momento rememorado, por uma fração de segundo, é (re)vivido como presente. Em consequência disso, o real se incorpora à representação simbólica que o sujeito faz daquele momento rememorado e revivido.

\section{O sujeito desejante: \\ deslizando da Psicanálise para a Análise do Discurso}

Para pensar o funcionamento desse sujeito, mobilizo inicialmente a reflexão de Guattari (1986). Para este autor, a produção da fala, das imagens, do desejo não tem origem no indivíduo. "Essa produção é adjacente a uma multiplicidade de agenciamentos sociais, [...] a mutações de universos de valor e de universos históricos" (GUATTARI \& ROLNIK, 1986, p. 32). E, mais adiante, acrescenta que tais "agenciamentos coletivos de subjetividade, em algumas circunstâncias [...], podem se individuar" (Ibidem, p. 33).

Entendo que é exatamente uma dessas formas de individuação que estamos observando pelo viés do processo metafórico em análise: aqui se individua, mesmo que por um instante, o sujeito desejante que se deixa perceber através dele.

Tomo essa concepção de sujeito desejante, pois as formulações de Guattari apresentam pressupostos possíveis de serem aproximados aos da AD. Em primeiro lugar, não se trata de considerar o sujeito em sua individualidade, mas de tomá-lo em seu agenciamento coletivo e social. Em segundo lugar, porque Guattari trata das pulsões ${ }^{5}$ como sintoma em nível do social e do político e não como sintoma individual. Para esse autor, a produção do desejo é resultante de pulsões de natureza político-social: "Trata-se, diz Guattari, de movimentos de protesto do inconsciente contra a subjetividade capitalística (sic), através de outras maneiras de ser, outras sensibilidades, outra percepção, etc." (Ibidem, nota 5, p. 45).

O autor chama a atenção para a importância política da produção do desejo e seus possíveis desdobramentos, entre os

5 A noção de pulsão foi formulada por Freud, 1915, em Instinto e suas Vicissitudes. Ela é resultante de uma pressão que se situa entre o mental e o somático e está na origem dos estímulos que se originam no corpo e alcançam a mente. Segundo Freud, a pulsão não se dá a conhecer por si mesma, mas é reconhecida pelas ideias (vostellung) e pelo afeto (affekt), sendo o afeto a expressão qualitativa da quantidade de energia pulsional, cujas manifestações são percebidas como sentimentos, e as ideias se produzem como traços de memória. quais se situariam os movimentos sociais. E é exatamente o que estamos constatando no caso em análise. Diolinda, ao tomar invasão por ocupação, é movida, por um lado, pela rememoração de um momento muito forte que a marcou e que ainda é capaz de emocioná-la, e, por outro, essa rememoração é resultante de uma pulsão político-social responsável pela emergência do sujeito desejante, sujeito este que luta pela justiça no campo, afrontando grandes proprietários de terra.

Tais formulações de Guattari têm início em seus escritos em coautoria com Deleuze (1972). Os autores postulam uma nova concepção de inconsciente, mobilizando a noção de economia em seu sentido pulsional e político. Afastam-se do inconsciente individual e vão ao encontro de um inconsciente em que jogam o funcionamento de fatores históricos, políticos, culturais e econômicos, daí surgindo um sujeito desejante capaz de pôr em questão a ordem 
estabelecida. E é isso que está em tela nesse trabalho: observar um processo metafórico que expõe a ação e palavra de um sujeito movido pelo agenciamento político do desejo.

Entendo que o processo metafórico ocupação/invasão identificado na SD5 funciona como o sintoma do sujeito desejante no discurso de Diolinda. Chamo a palavra de Rolnik para explicar essa emergência: "Se situarmos o inconsciente na maneira de se orientar e de se organizar no mundo - as cartografias que o desejo vai traçando [desenham] diferentes micropolíticas, que correspondem a diferentes modos de inserção social" (ROLNIK, 1986, p.12).

O processo metafórico em análise aponta para esses diferentes modos de inserção social trilhados por Diolinda. Em um primeiro momento, encontramos Diolinda jovem, participando de sua primeira ação política, ainda na companhia de seus pais. Dessa participação resultou o assentamento no qual sua família recebeu um lote de terra. Naquele momento, Diolinda era apenas uma jovem de 18 anos, filha de sem-terra, e acompanhava a ação política dos pais. Ainda não exercia função de liderança e podia mobilizar a designação invasão, comum entre assentados e acampados, para referir a luta pelo direito à terra. Nessa situação, movida pela pulsão político-social e pelas urgências típicas do cotidiano de acampados, subjetivou-se como um sujeito que desejava mudar o mundo, distinguindo-se do mundo capitalista em que vivia. $\mathrm{O}$ segundo momento nos coloca frente a Diolinda exercendo uma função de liderança entre os sem-terra acampados no Pontal de Paranapanema. E, nessa nova posição, Diolinda subjetiva-se, como vimos, pelo viés da designação ocupação. Modos diferentes de inserção social que conduzem a diferentes formas de designação.

Nesse passo do trabalho, o que importa analisar é a pulsão que está na base da oscilação/divisão/batimento do sujeito do discurso entre essas duas designações, ambas ocorridas num determinado momento da militância política de Diolinda e em uma mesma entrevista.

Como vimos, Diolinda divide-se, nessa entrevista, entre duas designações: uma que remete para o que deve e pode ser dito e que é resultante de sua interpelação ideológica e do lugar discursivo que ocupa como líder do MST. Desse lugar deve dizer e diz ocupação. Ao mesmo tempo, e contraditoriamente, a outra invasão - que aponta para o sentido impossível de dizer, a partir de seu lugar discursivo. Diolinda desliza, então, de um sentido para o outro. Dito de outra forma: este deslizamento marca o ponto em que se cruzam determinação ideológica - o que pode e deve ser dito - com determinação inconsciente, que sinaliza o sujeito desejante, capaz de mobilizar o discurso-outro. Esse ponto de encontro vem marcado por esta falha, esta passagem momentânea $e$ única de ocupação para invasão. É o interdiscurso que se atravessa no discurso do sujeito. Ouçamos uma vez mais o que diz Pêcheux: "a metáfora aparece fundamentalmente como uma perturbação 
que pode tomar a forma do lapso, do ato falho, do efeito poético, do Witz ou do enigma" (PÊCHEUX, [1984] 2011, p.160). Em meu entendimento, o deslizamento aqui em análise ocorre no momento em que a emoção aflora e faz o sujeito mover-se e dividir-se entre as duas designações. Trata-se de um efeito poético.

\section{Interrompendo a reflexão}

Mais acima, vimos que a pergunta feita à Diolinda pela entrevistadora funcionou como um estopim para a ocorrência dessa falha, produzindo um efeito devastador, jogando-a para fora dos limites de seu lugar discursivo de líder e do sentido que, desse lugar, lhe é imposto. E, assim, sob o efeito da emoção, do afeto, para retomar o termo empregado por Freud ${ }^{6}$, que a rememoração suscitou, o dizer desse sujeito transbordou dos limites que sua posição-sujeito e seu lugar discursivo lhe impõem, mostrando-se um sujeito fragmentado e dividido entre duas designações que identificam posições diversas.

Oscilando entre a posição do bom sujeito que diz o que o líder pode e deve dizer de seu lugar discursivo, e a posição do sujeito que, capturado pela rememoração, vai ao encontro do "impossível de dizer, impossível de não dizer de uma determinada maneira" (PÊCHEUX, [1981] 2004, p. 52), o sujeito vai entretecendo em seu discurso a contradição. A presença de tais designações, contraditórias entre si, são o sintoma de que certos limites vão se esgarçando na ordem política da língua e, por entre os desvãos que vão surgindo, o sujeito desejante emerge, enunciando sob o efeito da emoção vivida no passado, rememorada no presente, mas também sob efeito do que acabara de viver: ter sido presa para, dessa forma, ser pressionada a dizer onde se encontrava seu marido procurado pela polícia. Mas não apenas isso: ao ser encarcerada, foi separada de seu pequeno filho, que ficou, dessa forma, privado do amparo do pai e da mãe. São esses sentimentos e memórias que fizeram aflorar o processo metafórico aqui analisado, que fizeram o sujeito estampar a marca de seu desejo em seu dizer.

Como vimos, o sujeito, sob o efeito e força da emoção, ao responder à pergunta que lhe foi dirigida, sucumbe à própria incompletude e simboliza o interdito. E, ao fazê-lo, o sujeito desejante mostra-se tal como é: incompleto, heterogêneo e dividido em relação a si mesmo e ao lugar discursivo que ocupa e no qual se constitui enquanto sujeito Sem Terra. Incompleto porque os dizeres e sentidos que sua posição-sujeito lhe autoriza são insuficientes para dizer a emoção sentida, mescla de alegria e de dor, mescla de rememoração e atualização da luta pela terra, provocando o transbordamento dos sentidos Heterogêneo porque apropria-se do dizer do outro, que irrompe transversamente em seu discurso, instaurando em seu interior a diferença e a contradição. E dividido porque movimenta-se entre ocupação e invasão, entre o que lhe é 
possível dizer e o que lhe está interditado, mas que só pode ser dito daquela forma, naquele momento.

Pode-se, pois, afirmar que a incompletude, a heterogeneidade e a divisão do sujeito desejante desse discurso decorrem do jogo tenso entre o memorável, o dizível e o interdito, fazendo com que os sentidos extravasem seus limites e produzam o cruzamento entre discursos de posições-sujeito diversas e conflitantes. Ou talvez seja melhor dizer que o jogo tenso entre dizível e interdito acaba por borrar momentaneamente tais limites, dando lugar a esse cruzamento/transbordamento.

Assim, ao dividir-se na dualidade contraditória ocupação/ invasão, esse sujeito desejante se constitui como sujeito de seu discurso. Ao representar-se dividido, carrega a marca do outro, evidenciando que a unicidade do sujeito é imaginária e se desfaz frente às pulsões políticas que movem seu desejo de um mundo mais justo.

\begin{abstract}
In the present text, I resume the terms occupation/ invasion in order to investigate a very peculiar sense for invasion that appeared in an interview with Diolinda Alves de Souza, MST leader, in December 6, 1995, for the Variety leaflet of Folha de São Paulo. In this interview, I was interested in examining the process of subjectification/ identification in Deolinda's phrasing: in a certain moment, while referring to her first occupation, she uses the term invasion. In doing so, the interview does not address what the subject can/ must say from its discursive locus. This term does not correspond to the mode of subjectification in her Discursive Formation, so well defined in the interview until that point. This sliding of occupation to invasion, allows us to identify a specific metaphorical process. A metaphorical process is "a non-subjective process in which the subject is constituted" (Pêcheux, 1988:130). And more: metaphorical process consists of a "socio-historical process that serves as the foundation for the 'presentation' of objects to subjects" (idem, p.132). I understand that this specific metaphorical process allows us to discern the moment in which the political subject is thrown back into its memories from which he emerges as a desiring subject.
\end{abstract}

Keywords: discursive locus; subject position; discursive formation; metaphorical process; production of desire; pulsional socio-political agency; desiring subject. 


\section{REFERÊNCIAS}

ALTHUSSER, Louis. Análise crítica da teoria marxista. Rio de Janeiro: Zahar, 1967.

DELEUZE, Gilles; GUATTARI, Felix. L'anti-œdipe. Paris: Minuit, 1972.

FREUD, Sigmund. O instinto e suas vicissitudes. In: Ed. Standard Brasileira das obras Psicológicas completas de Sigmund Freud. vol. 14. São Paulo: Imago, 1974.

GADET, Françoise; PÊCHEUX, Michel. A lingua inatingível: o discurso na História e na Linguística. Trad. de Bethania Mariani \& Maria Elizabeth Chaves de Mello. Campinas: Pontes, 2004 [1981]. GRIGOLETTO, Evandra. Do lugar social ao lugar discursivo: o imbricamento de diferentes posições-sujeito. In: INDURSKY, Freda; LEANDRO FERREIRA, Maria Cristina (Orgs.). Análise do discurso no Brasil: mapeando conceitos, confrontando limites. São Carlos: Claraluz, 2007.

GUATTARI, Felix; ROLNIK, Suely. Micropolítica: cartografias do desejo. Petrópolis: Vozes, 1986.

ROLNIK, Suely. Apresentação. In: GUATTARI, Félix; ROLNIK, Suely. Micropolítica: cartografias do desejo. Petrópolis: Vozes, 1986.

INDURSKY, Freda. A fala dos quartéis e as outras vozes. Campinas: Ed. da UNICAMP, 1997.

De ocupação a invasão: efeitos de sentido no discurso do/sobre o MST. In: INDURSKY, Freda; LEANDRO FERREIRA, Maria Cristina. Os múltiplos territórios da Análise do Discurso. Porto Alegre: Sagra-Luzzatto, 1999.

. O entrelaçamento entre o político, o jurídico e a ética no discurso do/sobre o MST: uma questão de lugar-fronteira. Rev. ANPOLL, n. 12, p. 111-131, jan./jul. 2002.

. O político e o jurídico na constituição das subjetividades sociais. Gragoatá, Niterói, n. 18, p. 97-110, 1º sem. 2005.

. Identificação e contra-identificação: diferentes modalidades de subjetivação no discurso do/sobre MST. In: MARIANI, Bethania (Org.). A escrita e os escritos: reflexões em análise do discurso e psicanálise. São Carlos, SP: Claraluz, 2006.

PÊCHEUX, Michel. Semântica e discurso. Campinas: Ed. da UNICAMP, 1988 [1975].

. Delimitações, inversões, deslocamentos. Cadernos de Estudos Linguísticos, Campinas, n. 19, p. 7-24, jul./dez. 1990a [1982].

A análise de discurso: três épocas. In: GADET, F.; HAK, T. (Orgs.). Por uma análise automática do discurso. Campinas: Ed. da UNICAMP, 1990b [1982]. 
. O discurso: estrutura ou acontecimento. Campinas: Pontes, 1990c [1982].

Metáfora e interdiscurso. In: ORLANDI, Eni P. (Org.). Análise de Discurso: Michel Pêcheux. Campinas: Pontes, 2011 [1984]. 